\title{
Commentary Compulsive Seekers: Our take. Two Clinicians' Perspective on a New Animal Model of Addiction
}

\author{
David H Epstein*,I and William J Kowalczyk' \\ 'National Institute on Drug Abuse Intramural Research Program Treatment Section, Intramural Research Program, National Institute on Drug \\ Abuse, National Institutes of Health, Baltimore, MD, USA
}

Neuropsychopharmacology (2018) 43, 677-679; doi:I0.1038/npp.2017.I32; published online 26 July 2017

The rat model of alcohol seeking described by Giuliano and colleagues (this issue)-we will refer to it as the Giuliano model-is part of a welcome trend toward animal models that incorporate two cardinal features of human addiction, which are as follows: (a) the use of drugs despite an unfavorable ratio of benefits to harms and (b) the fact that only a minority of drug users become addicted.

Rats in the Giuliano model were trained on a chained schedule of reinforcement, so their seeking of alcohol (via a lever that made a second lever accessible) could be tested and manipulated separately from their taking of alcohol (via the second lever, which brought the opportunity to drink). The model was intended to provide a platform whereby interventions could break the seeking/taking chain at the earliest possible point.

Giuliano and colleagues used an alcohol-preferring strain of rats, all of which were initially given a two-bottle (alcohol/ water) choice task to confirm and quantify their bibulosity. All were then trained to acquire the seeking/taking response chain, using a random-interval 60-s schedule for seekinglever reinforcement and an FR1 schedule for taking-lever reinforcement.

With seeking/taking established, one group of rats was assigned to an 'instrumental exposure' condition (eight 2-h sessions, in which the taking lever was presented alone, with the FR1 schedule still in effect), and a smaller group was assigned to a 'one-bottle exposure' condition (eight 4-h sessions in which the alcohol solution was simply available for drinking in the home cage-which presumably resulted in greater lifetime exposure, though the difference is not reported).

Both groups then underwent a 'seeking-taking punishment phase,' in which the initial training conditions were modified so that $30 \%$ of responses on the seeking lever resulted in

\footnotetext{
*Correspondence: Dr DH Epstein, NIDA IRP Treatment Section, Intramural Research Program, National Institute on Drug Abuse, National Institutes of Health, 25I Bayview Blvd, BRC Building, Suite 200, Baltimore, MD 21224, USA, Tel: +443740 2328,

E-mail: david.epstein@nih.gov

Received 12 June 2017; accepted 14 June 2017; accepted article preview online 27 June 2017
}

footshock instead of access to the taking lever. Rats were heterogeneous in their responses to this intermittent punishment. Using cluster analysis, Giuliano and colleagues sorted the rats into those that persisted on the seeking lever ('compulsive' rats, 34\%), those that greatly reduced their seeking ('non-compulsive' rats, $30 \%$ ), and those that were 'intermediate' (the other 36\%). These phenotypes remained largely stable for 10 months of testing. They were not accounted for by baseline differences on the two-bottle alcohol/water choice, nor by history of alcohol exposure (ie, home-cage access $v s$ only instrumental access).

For 10 months after the punishment phase, the rats underwent an array of tests. In a progressive-ratio task using the taking lever only, the 'compulsive' rats had a higher breakpoint than the 'intermediate' and 'non-compulsive' rats. In a test of reinstatement after extinction, alcoholrelated cues reinstated responding on the seeking lever, especially for the 'intermediate' rats. Reinstated responding on the taking lever (presented after a seeking-lever response) did not clearly differ by compulsiveness phenotype, suggesting that the differential susceptibility to reinstatement was specific to seeking.

In separate tests, seeking-lever presses were reduced by systemic administration of the mu-opioid antagonist GSK1521498. The extent of the reduction seemed to vary complexly across 'compulsive,' 'intermediate' and 'noncompulsive' rats, and as a function of their behavioral history. Giuliano and colleagues emphasize that the reduction looked especially prominent in the 'compulsive' rats.

\section{THE GIULIANO MODEL: PART OF A PROMISING TREND}

As we said, the Giuliano model adds to a body of recent efforts to recognize that addiction is more than selfadministration of a drug in a consequence-free setting. Giuliano and colleagues' separation of seeking from taking adds a nuance, but may also introduce a (fixable) problem. The problem is the timing and arrangement of the contingencies. 
Timing of contingencies was already an issue in the punishment model made famous in Deroche-Gamonet et al, 2004. In that model, an operant response for cocaine resulted in cocaine and footshock simultaneously. That simultaneity of reward and punishment has been criticized gently in print (Vanderschuren et al, 2017) and more vociferously (not by us) in meetings we have attended. We have also heard a good rebuttal to that criticism. Yes, an addicted human chooses drug with knowledge about immediate reward and delayed punishment. And yes, a rat in the Deroche-Gamonet model chooses drug with knowledge about immediate, simultaneous reward and punishment. But for both the human and the rat, the reward and punishment come after the drug choice. That may be a close enough parallel, given the rat's constricted time horizons. Apparently there are no published data on just how constricted a rat's time horizons are in those circumstances. For monkeys, though, a delay as short as $10 \mathrm{~min}$ wipes out the ability of punishment to suppress cocaine taking (Woolverton et al, 2012). So, in rat models, any delay between choice and punishment would probably need to be very brief-but even a delay of $30 \mathrm{~s}$ (well within a rat's time horizon for postreinforcement signal processing; Meck, 1985; Secci et al, 2016) would boost ecological validity.

The complication that is specific to the Giuliano model is not just about the timing of punishment; it's about what is punished. The Giuliano rat learns that there may be a punishment for the drug-seeking choice, and that this punishment replaces drug-taking. On its face, persistent seeking in the Giuliano model looks like a human addict's persistence in 'copping' (purchasing a drug) despite the possibility of arrest, assault, or some other adverse outcome that replaces drug acquisition. But it is rarely the contingency faced by a recovering alcoholic who's tempted to have a drink.

Perhaps that does not matter. The Giuliano model still centers on a motivationally conflicted choice guided by probabilistic outcomes, which is the kind of choice that is central to watershed moments in addiction. The risky seeking choice made by a Giuliano rat does correspond to risky acquisition behaviors seen in addicted humans; perhaps alcoholics would evince similar behaviors if acquisition of alcohol were riskier than it typically is.

Even so, a sensible next step would be a series of parametric studies to clarify what aspects of addiction are being modeled in a Giuliano rat. The current data set is not so orderly as to make an open-and-shut case for the use of the model with no refinements. For example, it looks as if rats of all three phenotypes (including the 'noncompulsives') were vulnerable to reinstatement of alcohol seeking, with the 'intermediates' rather than the 'compulsives' leading the pack (Figure 3f, Giuliano et al, 2017; this issue). Even less orderly were the rats' responses to a mu-opioid antagonist (Figure 4, Giuliano et al, 2017; this issue), which brings us to our next point.

\section{THE MU-OPIOID MANIPULATION: PERHAPS NOT THE BIG STORY HERE}

As we said, the Giuliano model might provide a platform for breaking the seeking/taking chain at the earliest possible point. We have two caveats about that.
First, Giuliano and colleagues understate what naltrexone and nalmefene (the currently marketed medications for alcoholism) can do. Naltrexone and nalmefene do not merely offer 'reductions in the amount of alcohol consumed when individuals already have relapsed' (emphasis added). Rather, they prevent progression from a 'slip' (a single drink) to a bout of heavy drinking (O'Malley et al, 1996; Mason et al, 1999; Karhuvaara et al, 2007). That is prevention of relapse.

Of course, Giuliano and colleagues are correct to say that many alcoholics would benefit from a treatment that prevents the initial slip. But-second caveat-they overstate the case for a new, more selective mu antagonist, GSK1521498. They write: 'We have shown previously that this compound is more effective than naltrexone in reducing cue-controlled alcohol seeking and also alcohol drinking (Giuliano et al, 2015).' The actual findings, reported in the supplementary section of their 2015 paper, were as follows: (1) GSK1521498 was more potent (not more effective) than naltrexone, in some strains of rats, in some tests, and (2) naltrexone, like GSK1521498, prevented both seeking and taking of alcohol, with effect sizes that varied complexly across strains and exposure histories.

So our read of the data is that there is no reason to expect the treatment benefits of GSK1521498 to differ qualitatively from those of the less-selective mu antagonists already available-specifically, no reason to predict a differential effect on seeking a first drink $v s$ progression to heavy drinking. As for whether the possibly greater potency of GSK1521498 will mean greater effectiveness, that is more of an open question. The current data are not screaming for a clinical trial, but they do not militate against a clinical trial, either.

A greater benefit, however, will probably accrue from continued refinement of the behavioral model. As Giuliano and colleagues rightly point out, the current results show that a sample composed entirely of avid self-administerersalcohol-preferring rats-yielded only a small subset of punishment-resistant seekers. The identities of those punishment-resistant seekers were not predictable on the basis of their initial degree of preference for alcohol. We applaud this further step away from the assumption that selfadministration equals addiction or even proneness thereto.

\section{FUNDING AND DISCLOSURE}

This work was supported by NIDA intramural funds. The authors declare no conflict of interest.

\section{REFERENCES}

Deroche-Gamonet V, Belin D, Piazza PV (2004). Evidence for addiction-like behavior in the rat. Science 305: 1014-1017.

Giuliano C, Goodlett CR, Economidou D, Garcia-Pardo MP, Belin D, Robbins TW et al (2015). The novel $\mu$-opioid receptor antagonist GSK1521498 decreases both alcohol seeking and drinking: evidence from a new preclinical model of alcohol seeking. Neuropsychopharmacology 40: 2981-2992.

Giuliano C, Peña-Oliver Y, Goodlett CR, Cardinal RN, Robbins TW, Bullmore ET et al (2017). The individual vulnerability to compulsive alcohol seeking is dependent on the $\mu$-opioid receptor: 
evidence from a new model in rats. Neuropsychopharmacology (this issue).

Karhuvaara S, Simojoki K, Virta A, Rosberg M, Loyttyniemi E, Nurminen $\mathrm{T}$ et al (2007). Targeted nalmefene with simple medical management in the treatment of heavy drinkers: a randomized double-blind placebo-controlled multicenter study. Alcohol Clin Exp Res 31: 1179-1187.

Mason BJ, Salvato FR, Williams LD, Ritvo EC, Cutler RB (1999). A double-blind, placebo-controlled study of oral nalmefene for alcohol dependence. Arch Gen Psychiatry 56: 719-724.

Meck WH (1985). Postreinforcement signal processing. J Exp Psychol Anim Behav Process 11: 52-70.
O’Malley SS, Jaffe AJ, Rode S, Rounsaville BJ (1996). Experience of a "slip" among alcoholics treated with naltrexone or placebo. Am J Psychiatry 153: 281-283.

Secci ME, Factor JA, Schindler CW, Panlilio LV (2016). Choice between delayed food and immediate oxycodone in rats. Psychopharmacology 233: 3977-3989.

Vanderschuren LJMJ, Minnaard AM, Smeets JAS, Lesscher HMB (2017). Punishment models of addictive behavior. Curr Opin Behav Sci 13: 77-84.

Woolverton WL, Freeman KB, Myerson J, Green L (2012). Suppression of cocaine self-administration in monkeys: effects of delayed punishment. Psychopharmacology 220: 509-517. 